\title{
The Impact Of Death Anxiety On Quality Of Life Among Cancer Patients: A Case Of Bahawalpur And Multan District
}

\author{
Siraj Hussain ${ }^{1}$, Dawood Nawaz ${ }^{2}$, Maria Anwar Khan ${ }^{3}$, Taoqeer Nawaz ${ }^{4}$, Saadia Zia ${ }^{5}$ \\ ${ }^{1}$ Lecturer at Department of Sociology, Bahauddin Zakariya University Multan, Sub-Campus Lodhran, Pakistan \\ ${ }^{2}$ Associate Lecturer, Department of Public Administration, The Islamia University of Bahawalpur, Pakistan \\ ${ }^{3}$ Lecturer at Department of Psychology, Institute of Southern Punjab, Multan, Pakistan \\ ${ }^{4} \mathrm{M}$. Phil scholar at Ocean University of China \\ ${ }^{5}$ Lecturer at Department of Psychology, Institute of Southern Punjab, Multan, Pakistan. \\ ${ }^{1}$ siraj.raza@bzu.edu.pk, ${ }^{2}$ dawood.nawaz@iub.edu.pk
}

\begin{abstract}
The current study aimed to carved the impact of death anxiety on quality of life among cancer patients. The study focused to find out the difference of death anxiety in the context of gender and socio-demographic factors; and to seek out the impact of death anxiety on the quality of life of cancer patients. Purposive sampling technique was opted to collect the $\mathrm{N}=110$ cancer patients from Victoria hospital Bahawalpur and the Minar hospital Multan though the cross-sectional survey research design. The instrument was adopted from Lemming fear of death anxiety scale and WHOQOL. To cognizant the study Correlation t-test was computed which put forth that women cancer patients have a positive correlation between death anxiety and the quality of life. The conclusion is there is an impact of death anxiety on quality of life among patients who were hospitalized. Death anxiety has a negative impact on quality of life among cancer patients. Patients both male and female experience death anxiety at a certain level that may impact their quality of life, cancer patients who were hospitalized they have more death anxiety than other cancer patients. Septate Psychological counseling sessions can assist to decline the death anxiety among cancer patients.
\end{abstract}

Keywords

anxiety, death anxiety, quality of life, counseling, cancer patients

Article Received: 10 August 2020, Revised: 25 October 2020, Accepted: 18 November 2020

\section{Introduction}

The ordinary response to stress is called anxiety. It is the sentiment of distress or apprehension about the next happenings of life. Anxiety is the body's natural response to stress. It's a feeling of fear or trepidation about what is going to be happen. The first day of school, going to a job interview, or giving a speech may cause most people to feel fearful and nervous. But if the feelings of anxiety are extreme, last for longer than six months, and are interfering with the life, then it may have an anxiety disorders (Neimeyer, 2015).

Anxiety is associated with the various disorders. The first one is panic disorder which is experiencing the iterate attacks of panic during the unanticipated times. Individuals suffering from panic are awful of the upcoming panic incursions (Kierkegaard, 2013). Similarly, the second one is a phobia, it is the fear of specific activity, situation, and the object. However, there is an obsessive-compulsive disorder, which is the repetition of the illogical thoughts that leads individuals to act in a certain way at different times. There is another form of anxiety which is separation anxiety disorder that is getting afraid of the loss of intimate relationships and the loved ones (Craske et al. 2011).

Hedman et al. (2016) stated that the illness anxiety disorder also rises from the associated worries with the health status of the individuals. Lastly, the post-traumatic stress disorder has emerged following any traumatic incident. Feelings of anxiety may vary from individual to individual. They may appear in miner forms of butterflies in the stomach or to the extreme form of escalating heartbeat. Individuals may face the disconnection between the body and the mind. This may be manifested in the general sentiments of the worries or the particular association of fears with the events and the objects (Scarella, Boland, \& Barsky, 2019).

However general anxiety may have several symptoms; these are restlessness, fast breathing, high heartbeat rate, problems of sleeplessness, and trouble concentrating. As for as the anxiety attacks are concerned they transpire abruptly, or slowly but it is materialized into the stressful incident or the worst approaches later on. There is no unanimous cause of anxiety apprehended by the researchers. This may be acquainted with the combination of the brain chemistry, environmental and genetic factors (Krause, 2015).

\section{Literature Review}

Death anxiety is sentiments of one's own death; eventually, death anxiety is the feelings of the apprehension, dread, solicitude, and the process of ceasing to be or dying. Death anxiety may be regarding one's own or someone others (Halberstadt \& Halberstadt, 2016). There are three types of death anxiety, the first one is the predatory or death anxiety which emerges from the threat or being harmed. Predatory death anxiety can be observed in the dangerous situations, some external threat, and when the individual is at the stake of life. Predatory death anxiety catalysis the alternative resources for the individuals and fosters the fight or flight reaction. This is the organized effort to encounter the danger or flew away from that particular milieu (Langs, 2018). The second one is predation or predatory death anxiety. This kind of anxiety is contrived from some events when an 
individual decimates the other one whether mentally or physically. It is aligned with the cataleptic guilt, which, however, prepares individuals to make some rapid actions to harm others. The third one is the existential death anxiety (Beshai, \& Naboulsi, 2004). It is the most important form of anxiety. It is generated from the basic acquaintance that life must be ceased. Sometimes anxiety leads to the fear of death.

According to Sigmund Freud (1992), death anxiety is the pretentiousness for the in-depth means of distress. Individuals don't get afraid of death as no one perceives of their death. Unconscious is not subject to the negotiations or time passages-individuals cannot be afraid of the death because they have never experienced death before. However, human reactions to death are dynamic, complex and multifaceted. Death anxiety may contain the various meanings, pain and loneliness, ultimate loss life, uncertainty, finality, life flow disruption, annihilation, retribution and judgment, prematurity and violence of death (Paul \& Wong, 2007). Humans develop different meanings with respect to the events and objects in the physical environment. Consequently, individuals developed certain links with the death and the outcomes will vary according to positive or negative meanings. Death anxiety is considered a normal among the cancer patients (Lee et al. 2020).

Death anxiety is a significant event of these patients suffering from this chronic disease (Soygur, 2012). Those individuals who are having a meaningful or terminal cancer illness are more prone towards death anxiety. cancer is a group of diseases that is abnormal growth of the cells in the body. These cells are disseminated in the other parts of the body also. But they proliferate in an irrepressible manner. Death anxiety is found to be common among cancer ailed patients (Lee et al. 2020). Patients fall in the death the anxiety during the screening test of the cancer, awaiting the results of the test, on the therapy or treatment of the cancer, and those who are finally anticipating re-emerging of the cancer screening test (Bahrami, 2013).

Quality of life (QOL) refers to the accustomed wellbeing of the individuals and the society which possess the comprehensively positive and negative features of life. consequently, the quality of a good life is collective or the individual's expectations regarding life. The source of these expectations is culture, values, and the collectively set goals of the society (Gibson \& Robinson 2001). It is the distinguished criteria of the society where the achievements of members of the society are measured. Individuals desires and perceptions can be different according to their subjective approach. Quality of life is a combination of various kinds of indicators ranging from family, physical health, wealth, employment, religious beliefs, freedom, life security, education, and the environment.

Nevertheless, QOL is a different concept than the standards of living. WHO (2004) has a similar definition of quality of life, "the individual's perception of their position in life in the context of the culture and value systems in which they live and concerning their goals". Mental and physical health has a close relationship with the quality of life. Medical treatments or different ailments can have severe effects on the patients. Cancer patient's quality of life is affected badly due to various reasons (Khaddar, 2020). It can be observed in both ways subjective and objective among the cancer patients, first one includes the conceptions and apprehensions of cancer patients in the working perspectives while the second one refers to the ceasing of the sum of items or activities.

Death anxiety and the QOL of the cancer patients is not a labyrinth anymore. Patients have adverse consequences in their lives. They may be affected by the various kinds of psychological and other diseases. Nonetheless, individuals with firm religious beliefs can be a good fighter against cancer (Lee et al. 2020). Eventually, people are perplexed with the assumptions of death, this threat of death performs as a deterrent for any kind of inappropriate, undesirable, or any deviant act. But this fear of death has different associations with the variations of gender, age and the profession (Köhler, 2004).

It has been observed that older cancer patients do not have more fear of death than the youngsters. Furthermore, the female gender has more death anxiety levels than its opposite gender. In fact, fear is used as a reaction to the unknown situation, perhaps anxiety is also referred to as a response to the unknown phenomenon. Similarly, death anxiety is an unknown experience in cancer patients and it is also a strong label in their perceptions. Wong, Reker, and Gesser (1994) conceptualized death acceptance which includes three components: natural acceptance approach, acceptance to beliefs in the afterlife and escape acceptance (death as an alternative to miserable life).

It is important to realize that belief in an afterlife or immortality is one way to think about death as meaningful. Alternative ways may be related to a process of denying individualization in which the self tends to transcend its boundaries reuniting with the universe (Jenko, Gonzalez, \& Seymour, 2007). Apart from this, another major concept was given by Lewis and Butler, they are of the opinion that individuals life is not affected by the fear of the death but there persists the fear of credence in the meaninglessness of the life. Those having dissatisfaction, sentiments of aimlessness about their previous life experiences are more susceptible to death anxiety.

\section{Methodology}

The purpose of the research was to measure the relationship between the death anxiety and quality of life of cancer patients. To investigate the relationship between death anxiety and QOL, non-experimental research design was followed. Cancer patients were included in the study to investigate the impact of death anxiety on quality of life. Total 110 diagnose cancer patients with age range of 20-80 years were included in the study. The sample was collected from Victoria Hospital Bahawalpur and the Minar hospital Multan. Patients having cancer of any cite were included in the study. Both in-door and out-door patient patients were included in the study. The participants below 20 years and all other patients of hospitals were excluded from the study. Any patient having any other physical and psychological disorder was excluded from the study.

In this cross-sectional survey, the researcher used the random purposive sampling technique to collect the data. Two different scales were used for the measurement of death anxiety and quality of life. To measure the death anxiety, the lemming fear of the death anxiety scale 
(Lemming, 1982) was adopted. This scale was designed by the Weinter in 1982, this comprises of the 26 items along with 6 different categories ranging from the Strongly Disagree to the Strongly Agree. This scale possess the subcategories; fear of pain, dependency, separation, isolation, loneliness, leaving of loved ones, death and afterlife shocks.

Nevertheless, for the assessment of the quality of life researchers adopted the Australian World Health Organization Quality of Life Scale. The Australian World Health Organization Quality of life (WHOQOL) was developed in 1996 by World Health Organization Geneva. It is the combination of 26 items with the four scales. Four types of scales are used to assess intensity, frequency, capacity, and evaluation. After the data collection, the data was analyzed by using SPSS Version 21. Pearson correlation was used to check the correlation between death anxiety and quality of life. T-test were used to examine the difference level among demographic variables.

\section{Results, Findings \& Discussion}

Table 1: Demographic Characteristics

\begin{tabular}{lll}
\hline $\begin{array}{l}\text { Demographic } \\
\text { Characteristics }\end{array}$ & Frequency & Percentage \\
\hline Age & & \\
$20-30$ & 28 & 25.5 \\
$31-50$ & 38 & 34.5 \\
$51-60$ & 31 & 28.5 \\
$61-80$ & 13 & 8.5 \\
\hline Gender & & \\
Male & 59 & 53.6 \\
Female & 51 & 46.4 \\
\hline Qualification & & \\
Educated & 95 & 86.4 \\
Uneducated & 14 & 12.7 \\
\hline Occupation & & \\
Working & 67 & 60.9 \\
Non-working & 43 & 39.1 \\
\hline Hospitalized & & \\
Yes & 64 & 58.2 \\
No & 46 & 41.8 \\
\hline Socio-economic Status & & \\
Low income & 28 & 56.4 \\
Middle income & 62 & 17.3 \\
High income & 19 & \\
\hline
\end{tabular}

Table 1 shows the percentage of female $(\mathrm{N}=51)$ and male $(\mathrm{N}=59)$ in the study. Age range vary from 20 to 80 , but categories was made range from 20-30 total number of patients $(\mathrm{N}=28), 31-50$ total number of patients $(\mathrm{N}=38), 51$ 60 total number of patients $(\mathrm{N}=31)$, and $61-80$ total number of patients $(\mathrm{N}=13)$ was included in the study. Educated patients were $(\mathrm{N}=95)$ and uneducated was $(\mathrm{N}=14)$ included in the study. Both working patients $(\mathrm{N}=67)$ and nonworking $(\mathrm{N}=43)$ were included and the total number of hospitalized patients in the study was $(\mathrm{N}=64)$ and the total number of non- hospitalized patients was $(\mathrm{N}=46)$.
Table 2: Death Anxiety, Quality of life, Concerning the Gender

\begin{tabular}{|c|c|c|c|c|c|c|c|}
\hline \multirow{4}{*}{$\begin{array}{l}\text { Variab } \\
\text { les }\end{array}$} & \multicolumn{2}{|l|}{ Gender } & \multirow{4}{*}{$\begin{array}{l}\text { Mean } \\
\text { Differe } \\
\text { nce }\end{array}$} & \multirow{4}{*}{$\begin{array}{l}\text { Std. } \\
\text { Error } \\
\text { Differe } \\
\text { nce }\end{array}$} & \multirow[t]{4}{*}{$t$} & \multicolumn{2}{|c|}{$95 \% C I$} \\
\hline & \multicolumn{2}{|c|}{$\operatorname{Male}(n=\operatorname{Female}(n$} & & & & & \\
\hline & 59) & $=51)$ & & & & & \\
\hline & $M(S D)$ & $M(S D)$ & & & & $L L$ & $\boldsymbol{U L}$ \\
\hline Death & 14.30 & 14.60 & -.30276 & .80294 & & 41.894 & 2.632 \\
\hline Anxiet & $(4.25)$ & $(13.75)$ & 1.67431 & 1217276 & 7 & 32 & 48 \\
\hline $\mathrm{y}$ & 14.60 & 81.90 & & & & 01.288 & 5.981 \\
\hline $\begin{array}{l}\text { Quality } \\
\text { of Life }\end{array}$ & $(4.13)$ & $(7.70)$ & & & 7 & 81 & 10 \\
\hline
\end{tabular}

Note: Results of the table indicate that gender of cancer patients is significantly affect the Quality of life of cancer patients.

In Table 2 below, t-test was applied to compare females and males to measure the impact of quality of life on cancer patient. The female in this research having $\mathrm{M}=81.90, \mathrm{SD}=$ 7.70 and male in this research having $\mathrm{M}=14.60, \mathrm{SD}=4.13$ and $t$ value is .007 . The result shows that there is significant level of quality of life among females than males in cancer patients.

Table 3: Death Anxiety, Quality of life, with regard to the Hospitalized

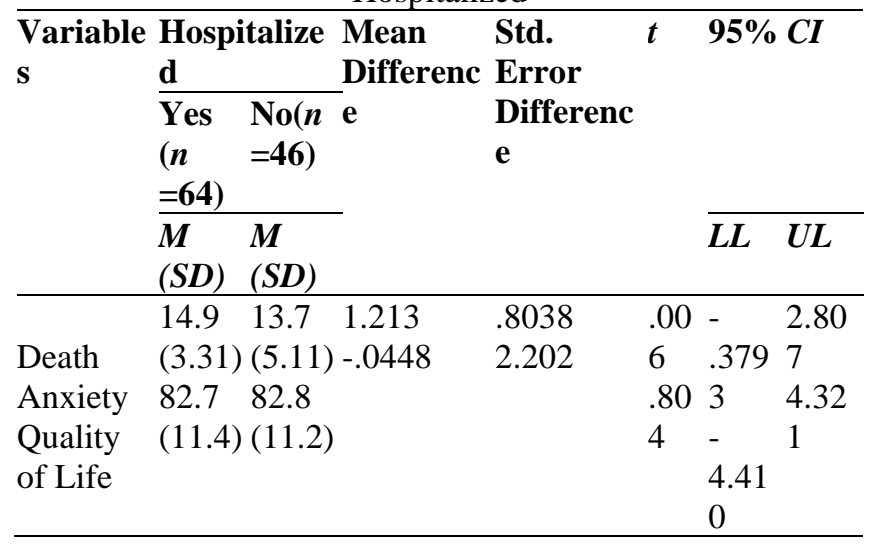

Note: Results of the table indicate that hospitalized cancer patients significantly affect the Death anxiety of patients.

Table 3 t-test was applied to compare hospitalized and nonhospitalized to measure the impact of death anxiety on quality of life. The hospitalized in the research having $\mathrm{M}=14.9 \mathrm{SD}=3.31$ and non- hospitalized having $\mathrm{M}=13.7$ $\mathrm{SD}=5.11$ and $\mathrm{t}$ value is .006 for death anxiety. The result shows that there is a significant level of death anxiety in cancer patients who are hospitalized than those who are not. Table 4: Descriptive Statistics and Correlations of Variable

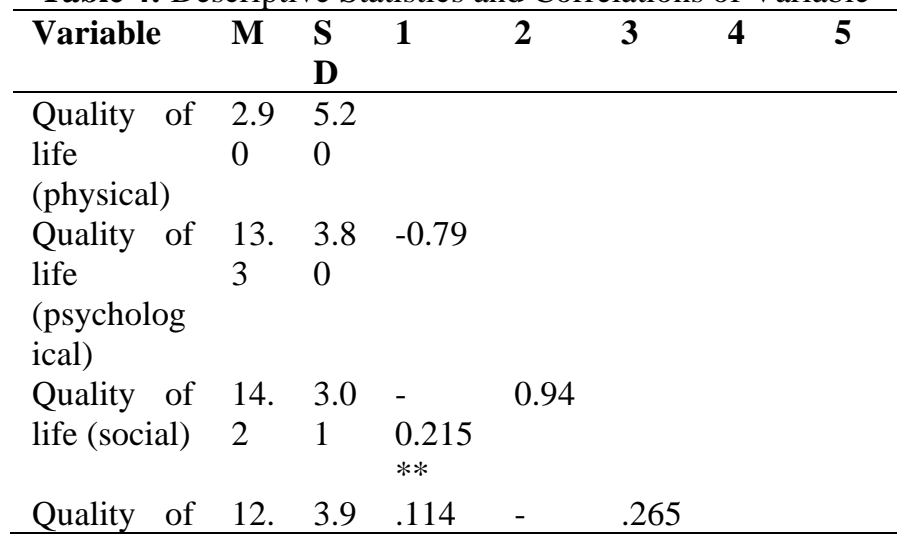




$\begin{array}{lllllllll}\begin{array}{l}\text { life } \\ \text { (environme }\end{array} & 9 & 9 & & 0.32 & * * & & \\ \text { ntal) } & & & & & & & \\ \text { Total } & 82 . & 11 . & .348^{*} & .453 & .339 & .804 & - \\ \text { Quality of } & 8 & 3 & * & * * & * * & * * & .13 \\ \text { life } & & & & & & & 9 \\ \text { Total } & 14 . & 4.1 & -2.66 & - & .124 & - & \\ \begin{array}{l}\text { Death } \\ \text { Anxiety }\end{array} & 4 & 8 & & 0.28 & & .041 & \\ & & & & & & & \end{array}$

**. Correlation is significant at the 0.01 level (2-tailed).

*. Correlation is significant at the 0.05 level (2-tailed).

Table 4 descriptive correlation illustrates the result that quality of life 1 with $\mathrm{M}=2.90, \mathrm{SD}=.520$ has no significant correlation. Quality of life 2 with $\mathrm{M}=13.3, \mathrm{SD}=3.80$ has negative correlated -.079 with quality of life 1 . Quality of life 3 with $\mathrm{M}=14.2, \mathrm{SD}=3.01$ has $-0.215^{*}$ with quality of life 1 at a significant level 0.05 . Quality of life 4 has $-265^{* *}$ negative correlated with quality of life 3 at a significant level 0.01 . The overall correlation indicated with quality of life has $\mathrm{M}=82.8, \mathrm{SD}=11.3$ has a significant correlation $.348 * *$ at significant level 0.01 with quality of life $1, .453 * *$ significant correlation at significant level 0.01 with quality of life 2, quality of life 3 has a significant correlation .339** at significant level 0.01 with total quality of life. Quality of life 4 having a significant correlation $.804 * *$ with total quality of life at a significant level 0.01 . Death anxiety with $\mathrm{M}=14.4, \mathrm{SD}=4.18$ having a significant correlation with quality of life $1,-.266^{* *}$ at significant level 0.01 .

The first hypothesis of the study was that quality of life has a positive correlation among females than males. Findings of the study illuminated that female cancer patients have a significant level of quality of life as compare to the male cancer patients. on the other hand, Conversano et al. (2010) carved out the results that men have more quality of life as compared to women. The reason for the occurrence of differences in quality of life between both gender can be the socio-cultural context of the respondents that contributed to these differences. This study found that death anxiety has more strong relationship with the socio-demographic factors, this has a slight contradiction with the Sherman (2010) that death anxiety is moderate among the cancer patients with the different socio-demographic factors.

The results of Bahrami et al. (2013) study on women with breast cancer shows moderate to high death anxiety among them Bahrami et al. (2013). Furthermore, this study put forth that there is a significant relationship between the death anxiety and the quality of life of cancer patients, nonetheless a study conducted by soleimani et al. (2016) explores that there is an inverse relationship between death anxiety and the quality of life. Similarly, (Bonder et al. 2015) endorses our findings that there is a strong relationship between death anxiety and the quality of life of cancer patients.

\section{Conclusion}

Dying is an experience that can only be imagined, thereby fueling the fear of death. The present study propounded to seek out the relationship between death anxiety and the quality of life among cancer patients. The study concluded that death anxiety can be increased by the decline of various factors of the social life, psychological, physiological domain, and the environmental aspects.

Despite this, it has been observed that anxiety is the natural outcome of after the cancer is diagnosed in the patients. However, it may vary with the patient's perception of disease, education or religious attachment. Accordingly, the quality of life of the patients may be fluctuating with respect to the different factors. On the basis of indications of the study, it is suggested that to have a balance between the death anxiety and the quality of life cancer patients must be provided with the counseling sessions and the psychotherapy programs.

\section{References}

[1] Bahrami, N., Moradi, M., Soleimani, M. A., Kalantari, Z., \& Hosseini, F. (2013). Death anxiety and its relationship with quality of life in women with cancer. Iran Journal of Nursing, 26(82), 51-61.

[2] Barrett, H. C. (2015). Adaptations to predators and prey. The handbook of evolutionary psychology, 1-18.

[3] Beshai, J. A., \& Naboulsi, M. A. (2004). Existential perspectives on death anxiety. Psychological Reports, 95(2), 507-513.

[4] Carr, A. J., Gibson, B., \& Robinson, P. G. (2001). Is quality of life determined by expectations or experience? Bmj, 322(7296), 1240-1243.

[5] Conversano, C., Rotondo, A., Lensi, E., Della Vista, O., Arpone, F., \& Reda, M. A. (2010). Optimism and its impact on mental and physical well-being. Clinical practice and epidemiology in mental health: CP \& $\mathrm{EMH}, 6,25$.

[6] Craske, M. G., Rauch, S. L., Ursano, R., Prenoveau, J., Pine, D. S., \& Zinbarg, R. E. (2011). What is an anxiety disorder? Focus, 9(3), 369-388.

[7] Freud, S., \& Freud, E. L. (1992). Letters of Sigmund Freud. Courier Corporation.

[8] Gonen, G., Kaymak, S. U., Cankurtaran, E. S., Karslioglu, E. H., Ozalp, E., \& Soygur, H. (2012). The factors contributing to death anxiety in cancer patients. Journal of psychosocial oncology, 30(3), 347-358. 
[9] Gonen, G., Kaymak, S. U., Cankurtaran, E. S., Karslioglu, E. H., Ozalp, E., \& Soygur, H. (2012). The factors contributing to death anxiety in cancer patients. Journal of psychosocial oncology, 30(3), 347-358.

[10] Götze, H., Brähler, E., Gansera, L., Schnabel, A., Gottschalk-Fleischer, A., \& Köhler, N. (2018). Anxiety, depression and quality of life in family caregivers of palliative cancer patients during home care and after the patient's death. European journal of cancer care, 27(2), e12606.

[11] Hedman, E., Axelsson, E., Andersson, E., Lekander, M., \& Ljotsson, B. (2016). Exposure-based cognitive-behavioural therapy via the internet and as bibliotherapy for somatic symptom disorder and illness anxiety disorder: randomised controlled trial. The British journal of psychiatry, 209(5), 407-413.

[12] Kierkegaard, S. (2013). The concept of anxiety (pp. 1-6). Princeton University Press.

[13] Krause, S., Rydall, A., Hales, S., Rodin, G., \& Lo, C. (2015). Initial validation of the Death and Dying Distress Scale for the assessment of death anxiety in patients with advanced cancer. Journal of pain and symptom management, 49(1), 126-134.

[14] Krause, S., Rydall, A., Hales, S., Rodin, G., \& Lo, C. (2015). Initial validation of the Death and Dying Distress Scale for the assessment of death anxiety in patients with advanced cancer. Journal of pain and symptom management, 49(1), 126-134.

[15] Langs, R. (2018). Death anxiety and clinical practice. Routledge.

[16] Lee, S. A., Jobe, M. C., Mathis, A. A., \& Gibbons, J. A. (2020). Incremental validity of coronaphobia: Coronavirus anxiety explains depression, generalized anxiety, and death anxiety. Journal of anxiety disorders, 74, 102268.

[17] Neimeyer, R. A. (Ed.). (2015). Death anxiety handbook: Research, instrumentation, and application. Taylor \& Francis.
[18] Scarella, T. M., Boland, R. J., \& Barsky, A. J. (2019). Illness anxiety disorder: psychopathology, epidemiology, clinical characteristics, and treatment. Psychosomatic medicine, 81(5), 398-407.

[19] Seymour, M. T., Maughan, T. S., Ledermann, J. A., Topham, C., James, R., Gwyther, S. J., ... \& Meade, A. M. (2007). Different strategies of sequential and combination chemotherapy for patients with poor prognosis advanced colorectal cancer (MRC FOCUS): a randomised controlled trial. The Lancet, 370(9582), 143-152.

[20] Sherman, D. W., Norman, R., \& McSherry, C. B. (2010). A comparison of death anxiety and quality of life of patients with advanced cancer or AIDS and their family caregivers. Journal of the Association of Nurses in AIDS Care, 21(2), 99-112.

[21] Soleimani, M. A., Lehto, R. H., Negarandeh, R., Bahrami, N., \& Chan, Y. H. (2017). Death anxiety and quality of life in Iranian caregivers of patients with cancer. Cancer nursing, 40(1), E1-E10.

[22] Tomer, A., Eliason, G. T., \& Wong, P. T. (Eds.). (2007). Existential and spiritual issues in death attitudes. Psychology Press.

[23] Wong, P. T., Reker, G. T., \& Gesser, G. (1994). Death Attitude Profile-Revised: A multidimensional measure of attitudes toward death. Death anxiety handbook: Research, instrumentation, and application, 121 